\title{
Teachers and students perception about the present status of undergraduate dental curriculum in Bangladesh
}

\author{
Dr. Md. Rasel Ahmad', Prof. Dr. Iffat Ara', Prof. Md. Humayun Kabir Talukder ${ }^{3}$, Dr. Md. Immam Hossin ${ }^{4}$ \\ Brig Gen (Dr) Md Abdullah Al Harun ${ }^{5}$ Brig Gen (Dr) Dipak Kumar Paul Chowdhury, Prof. Dr. Mohammad Faruque
}

\begin{abstract}
Background: Bachelor of dental surgery course curricula need to be constantly analyzed and evaluated in order to offer dental courses in accordance with current technical innovations of dentistry as well as the demands of community oral health. Under the assumption that it is important to comprehend some students' perceptions, the present study aims to analyze students' perceptions regarding dental courses, embracing the academic environment, and describe the current scientific published literature about this research object. Specifically, it aims to access and synthesize the scientific knowledge involving students' perceptions regarding dental courses, by means of constructing thematic categories classifying its levels of evidences. Objectives: The present study was undertaken to identify the teachers and students perception about the present status of undergraduate dental curriculum in Bangladesh.
\end{abstract}

Methods: This descriptive type of cross sectional study was conducted in seven public and private dental colleges of Bangladesh after getting written permission from the principal of the respective dental colleges. Voluntary participation of the students was ensured and the names of the students' as well as teachers were kept confidential. The teachers and students of final years from the different dental colleges were the study population; among them four hundred (400) students and one hundred twenty teachers (120) were taken as sample by convenient sampling. Data collection instrument was a semistructured questionnaire with 5-point Likert scale with maximum score 5 and minimum score 1 for final year students' and in depth interview was used for teachers.

Results: $87 \%$ teachers mentioned that the total hours for practical/clinical classes in individual subject are inadequate. $63 \%$ teachers mentioned that the total hours for lecture classes in individual subject are inadequate. The overall results regarding the competency acquired by the newly passed dental graduate from the BDS course was satisfactory but some problematic areas were highlighted which interfered in achieving their satisfaction on their competencies

Conclusion: In this study, the students reported that they have acquired greater practical and clinical experiences in few areas from the curriculum of BDS course. The majority of the students were not satisfied on their acquired competencies in most of the areas after their graduation. This was due to shortage of course duration in comparison to number of subjects and contents, improper distributions of the subjects, inadequate duration of community placement, less allocation of hours in practical and clinical classes etc. According to their opinion, lack of supervision and feedback in the clinical class, improper method of clinical assessment system of the students in all level are the responsible factors so that the students were not satisfied with the overall undergraduate BDS curriculum.

Key Words: Teachers perception, Clinical teaching, Assessment system, Learning environment, Students' perceptions, Dental curriculum.

\section{Introduction}

The modern concept of a curriculum, originally derived

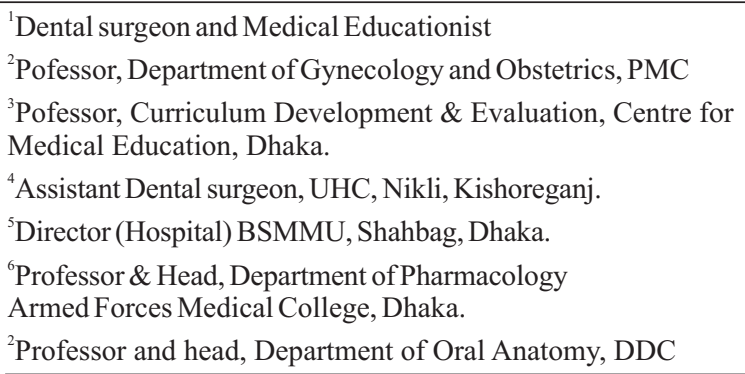

${ }^{1}$ Dental surgeon and Medical Educationist

${ }^{2}$ Pofessor, Department of Gynecology and Obstetrics, PMC

${ }^{3}$ Pofessor, Curriculum Development \& Evaluation, Centre for

Medical Education, Dhaka.

${ }^{4}$ Assistant Dental surgeon, UHC, Nikli, Kishoreganj.

${ }^{5}$ Director (Hospital) BSMMU, Shahbag, Dhaka.

${ }^{6}$ Professor \& Head, Department of Pharmacology

Armed Forces Medical College, Dhaka.

${ }^{2}$ Professor and head, Department of Oral Anatomy, DDC

Address of correspondence: Dr. Md. Rasel Ahmad

BDS (DDC), MMEd (BSMMU), FICD (USA)

Dental Surgeon and Medical Educationist

Email: raselbds42@gmail from the Latin word for a race course, was first described in depth in a book by J. F. Bobbitt in the early twentieth century.1 His ideas were modern in that he described the curriculum as a series of learning experiences to which a child ought to be exposed on the journey or course, to adulthood. It encompassed taught school lessons as well as school ethos, plus societal pressures and mores $\mathrm{He}$ understood the power of what is now known as the 'hidden curriculum'2,3 and importantly, what society needed in its adult population. In other words a curriculum should be ?t for purpose. He realized that curricula were values driven and built upon the designer's beliefs about what a successful student should know, and how they should best get to know these things. What is crucial, then and now a hundred years later, is that those designer's values are up-to-date, relevant to need, and fit he prevailing circumstances. It is also

Bangladesh Journal of Medical Education 2016;7(2):28-33. C 2016 Ahmed et al., publisher and licensee Association for Medical Education. This is an Open Access article which permits unrestricted non-commercial use, provided the original work is properly cited. 
desirable, in a health care profession curriculum that the values underpinning the syllabus should be similar to or symbiotic with, the values underpinning the health services in which the students are to practice after graduation, wherever that may be worldwide. This current paper focuses on the content of the curriculum; that is the 'what' and how it was determined. Curriculum is much more than is generally understood by the term 'syllabuses'. Colest (1985) cited from Coles (1985) that a useful way of conceptualizing curriculum is by considering it as comprising three more or less overlapping circles. The first circle represents the 'Curriculum on paper' and it includes written documents, prospectuses, committee minutes, course descriptions, its purpose, aims, goals and the intentions of the people involved. The second circle called the 'curriculum in action' it consists of timetabled events, lectures, tutorials, seminars, practices visits wards and so on. It is then a representation of how the intentions reflected in first circle, appear in practice. Hence there is lack of perfect overlap of the two circles. The third circle represents' 'the curriculum students experienced'. It is what students do, how they study, what they believe they should be doing, the learning that occurs and its outcomes again there is an incomplete overlap between this circle and the other two. In medical education, much attention has been paid to curriculum development (Harden, 1986). Emphasis has been placed on educational strategies such as student-centered learning, problem based learning, integrated teaching and community-based teaching (Harden et al 1984). Dentistry is a profession that requires a broad understanding of a spectrum of healthcare and basic sciences, together with specific education in oral sciences. In preparation for graduation, students must demonstrate a variety of acquired learning outcomes, which, in turn demand variety in learning and teaching methods. In order to educate a dentist to become competent, learning and teaching methods should be based on educational need. Teaching should be student-centred and flexible, supporting a variety of learning styles, yet main- training a balance between the educational needs of the student and the absolute requirement that the learning objectives are attained.

\section{Methodology}

This descriptive type of cross sectional study was conducted in seven public and private dental colleges of Bangladesh after getting written permission from the principal of the respective dental colleges. Voluntary participation of the students was ensured and the names of the students' as well as teachers were kept confidential. The teachers and students of final years from the different dental colleges were the study population; among them four hundred (400) students and one hundred twenty teachers (120) were taken as sample by convenient sampling. Data collection instrument was a semi-structured questionnaire with 5-point Likert scale with maximum score 5 and minimum scorelfor final year students' and in depth interview was used for teachers. The instruments were pretested in Rajshahi city, which was far away from the study area (Dhaka city). The researcher himself visited selected dental colleges. He was introduced himself to the principal of the dental colleges, course coordinators and the teachers of all departments to conduct the study. Specific time was taken from the class teacher to brief the students about the purpose and benefit of the study. The students were briefed about the questionnaire. The investigator himself collected all the data with prior permission of the principles and heads of the concerned departments. The semi-structured questionnaire was prepared on the basis of undergraduate dental curriculum2007. Before administering the questionnaires to the respondents the investigator gave them an introductory idea about the purpose of the research. The respondents who wish to spent sufficient time were interviewed in-depth interview. All the collected data were checked manually. Data entry, editing, processing and analysis have been done by using 19 version of SPSS compute software programme. Interpretations were done subsequently. Data were presented by tables and graphs with necessary description where necessary for easy understanding and interpretation. Results of in-depth interviews were presented by qualitative descriptions. Necessary permissions were taken from all the concerned authorities to conduct the study.

\section{Results}

Table 1 shows out of 100 teachers majority 98(98.0) mentioned that the total course duration should be 5 years and 2(2.0) mentioned that the course duration should be 4 years.

Table 1: Distribution of the teachers by their opinion regarding the duration of the course

\begin{tabular}{|l|c|c|}
\hline $\begin{array}{l}\text { Duration of the course according } \\
\text { to the teachers opinion }\end{array}$ & Frequency & Percent \\
\hline 5 years & 98 & 98.0 \\
\hline 4 years & 2 & 2.0 \\
\hline Total & 100 & 100.0 \\
\hline
\end{tabular}

Table 2 shows allocation of hours for practical/clinical classes in individual subject. Out of 100 teachers 2(2.0) mentioned that the allocation of hours for practical/clinical lecture classes in Anatomy with Histology should be 80 hours, 2(2.0) mentioned that the allocation of hours for practical/clinical classes in Physiology with Biochemistry should be76 hours, 6(6.0) mentioned that the allocation of hours for practical/clinical classes in Science of Dental Materials should be 78 hours, 7(7.0) mentioned that the allocation of hours for practical/clinical classes in General and Dental pharmacology should be 50.5 hours, 3(3.0) mentioned that the allocation of hours for practical/clinical classes in Pathology and Microbiology should be 90 hours, 5(5.0) mentioned that the allocation of hours for practical/clinical classes in Oral Anatomy and Physiology should be 51 hours, $8(8.0)$ mentioned that the allocation of hours for practical/clinical classes in Dental Public Health should be 55 hours, 2(2.0) mentioned that the allocation of hours for practical/clinical classes in General Medicine should be 70 hours, 2(2.0) mentioned that the allocation of

Bangladesh Journal of Medical Education 2016;7(2):28-33. 
hours for practical/clinical classes in General Surgery should be 76 hours, 10(10.0) mentioned that the allocation of hours for practical/clinical classes in Periodontology and Oral pathology should be 50 hours, 12(12.0) mentioned that the allocation of hours for practical/clinical classes in Oral and Maxillofacial surgery should be 90.0 hours, 16(16.0) mentioned that the allocation of hours for practical/clinical classes in Conservative Dentistry and Endodontics should be 140.0 hours, 6(6.0) mentioned that the allocation of hours for practical/clinical classes in Prosthodontics should be 110 hours, $9(9.0)$ mentioned that the allocation of hours for practical/clinical classes in Orthodontics should be 110 hours, 7(7.0) mentioned that the allocation of hours for practical/clinical classes in Paediatric Dentistry should be 110.5 hours.

Table 2: Distribution of the teachers by their opinion regarding the allocation hours for the practical/clinical classes

\begin{tabular}{|l|c|c|c|}
\hline $\begin{array}{l}\text { Allocation hours for the } \\
\text { practical/clinical classes }\end{array}$ & Frequency & Percent & $\begin{array}{c}\text { Mean } \\
\text { (Hours) }\end{array}$ \\
\hline Anatomy with Histology & 2 & 2.0 & 80 hours \\
\hline Physiology with Biochemistry & 2 & 2.0 & 76 hours \\
\hline Science of Dental Materials & 6 & 6.0 & 78 hours \\
\hline $\begin{array}{l}\text { General and Dental } \\
\text { pharmacology }\end{array}$ & 7 & 7.0 & 50.5 hours \\
\hline Pathology and Microbiology & 3 & 3.0 & 90 hours \\
\hline Oral Anatomy and Physiology & 5 & 5.0 & 51 hours \\
\hline Dental Public Health & 8 & 8.0 & 55 hours \\
\hline General Medicine & 2 & 2.0 & 70 hours \\
\hline General Surgery & 2 & 2.0 & 76 hours \\
\hline $\begin{array}{l}\text { Periodontology and Oral } \\
\text { pathology }\end{array}$ & 10 & 10.0 & 50 hours \\
\hline Oral and Maxillofacial surgery & 12 & 12.0 & 90 hours \\
\hline $\begin{array}{l}\text { Conservative Dentistry and } \\
\text { Endodontics }\end{array}$ & 16 & 16.0 & 140 hours \\
\hline Prosthodontics & 6 & 6.0 & 110 hours \\
\hline Orthodontics & 8 & 8.0 & 110 hours \\
\hline Paediatric Dentistry & 7 & 7.0 & 110.5 hours \\
\hline Total & 96.0 & \\
\hline
\end{tabular}

Table 3 shows out of 398 students majority 262(65.8) mentioned very satisfied, 133(33.4) satisfied and 3(.8) neither satisfied nor dissatisfied in performing of scaling. Out of 397 students majority 198(49.9) mentioned very satisfied, 182(45.8) satisfied, 12(3) neither satisfied nor dissatisfied in performing of operculectomy. Out of 398 students majority 289(72.6) mentioned satisfied, 40(10.1) very satisfied, 69(17.3) neither satisfied nor dissatisfied in performing gingivectomy. Majority 289(72.6) mentioned satisfied, 40(10.1) very satisfied and 69(17.3) neither satisfied nor dissatisfied in performing scaling and periodontal pocket curettage. Out of 396 students majority 286(72.2) mentioned satisfied, 87(22) very satisfied and
23(5.8) neither satisfied nor dissatisfied in performing pulpotomy. Out of 398 students majority 209(52.5) mentioned satisfied, 115(28.9) very satisfied and 74(18.6) neither satisfied nor dissatisfied in performing of pulpectomy. Out of 397 students majority 172(43.3mentioned very satisfied, 160(40.3) satisfied and 50(12.6) neither satisfied nor dissatisfied 15(3.8) dissatisfied in performing deciduous tooth restoration. Out of 393 students majority 172(43.8) mentioned very satisfied, 163(40.8) satisfied and 34(8.7) neither satisfied nor dissatisfied 24(6.1) dissatisfied and in performing deciduous tooth extraction. Out of 398 students majority 297(74.6) mentioned satisfied, 36(9) very satisfied, 59(14.8) neither satisfied nor dissatisfied and 6(1.5) dissatisfied in performing taking impression. On the other hand majority 177(44.5) mentioned satisfied, 27(6.8) very satisfied, 174(43.5) neither satisfied nor dissatisfied and 20(5) dissatisfied in constructing partial denture. out of 393 students majority 158(39.5) mentioned dissatisfied, 121(30.8) satisfied, 13(3.3) very satisfied, 97(24.7) neither satisfied nor dissatisfied and 4(1) very dissatisfied in constructing complete denture. Out of 400 respondents majority 148(37) mentioned dissatisfied, 87(21.8) satisfied, $27(6.8)$ very satisfied, $90(22.5)$ neither satisfied nor dissatisfied and 48(12) very dissatisfied in preparing tooth for metal ceramic crown. Out of 392 students majority 257(65.6) mentioned satisfied, 51(13) very satisfied, 59(15.1) neither satisfied nor dissatisfied and 24(6.1) dissatisfied and 1(.3) very dissatisfied in constructing removable appliance. Out of 395 students majority 239(60.5) were satisfied, 91(23) very satisfied, 36(9.1) neither satisfied nor dissatisfied and 27(6.8) dissatisfied and 2(.5) very dissatisfied in orthodontic diagnosis and treatment planning. Out of 397 students majority 300(75.6) mentioned satisfied, 65(16.4) very satisfied, 21(5.3) neither satisfied nor dissatisfied and 11(2.8) dissatisfied in treatment of different malocclusions using removable appliance. Out of 397 students majority 263(66.2) mentioned satisfied, 26(6.5) very satisfied, 105(26.4) neither satisfied nor dissatisfied and 3(.8) dissatisfied in preparing class 1 , class 2 , class 3 , class 4 and class 5 cavities.

Majority 269(67.3) mentioned satisfied, 35(8.8) very satisfied, 87(21.9) neither satisfied nor dissatisfied, 4(1) dissatisfied and 2(.5) very dissatisfied in preparing class 1 , class 2, class 3, class 4 and class 5 cavities. Majority 244(61.5) mentioned satisfied, 100(25.2) very satisfied, 49(12.3) neither satisfied nor dissatisfied and 4(1) dissatisfied in performing root canal treatment (RCT) of anterior and posterior teeth. Majority 269(67.8) mentioned satisfied, 112(28.2) very satisfied and 16(4) neither satisfied nor dissatisfied in performing extraction of anterior and posterior teeth. Out of 396 students majority 234(59.1) mentioned satisfied, 64(16) very satisfied, 66(16.7) neither satisfied nor dissatisfied and 32(8.1) dissatisfied in performing minor surgery cysts, tumors, apisectomy etc. 
Table 3: Distribution of the students by their opinion regarding the clinical competencies

\begin{tabular}{|c|c|c|c|c|c|c|}
\hline \multirow[b]{2}{*}{ Statement in relation to clinical competencies } & \multicolumn{5}{|c|}{ Frequency No (\%) } & \multirow[b]{2}{*}{ Total } \\
\hline & $\begin{array}{l}\text { VD } \\
(1)\end{array}$ & $\begin{array}{l}\text { D } \\
(2)\end{array}$ & $\begin{array}{l}\text { NSND } \\
(3)\end{array}$ & $\begin{array}{l}S \\
(4)\end{array}$ & $\begin{array}{l}\text { VS } \\
(5)\end{array}$ & \\
\hline Performing scaling & - & - & $3(.8)$ & $133(33.4)$ & $262(65.8)$ & 398 \\
\hline Performing operculectomy & - & $5(1.3)$ & $12(3)$ & $182(45.8)$ & $198(49.9)$ & 397 \\
\hline Performing gingivectomy & - & - & $69(17.3)$ & $289(72.6)$ & $40(10.1)$ & 398 \\
\hline Performing scaling periodontal pocket curettage & - & - & $69(17.3)$ & $289(72.6)$ & $40(10.1)$ & 398 \\
\hline Performing pulpotomy & - & - & $23(5.8)$ & $286(72.2)$ & $87(22)$ & 396 \\
\hline Performing pulpectomy & - & - & $74(18.6)$ & $209(52.5)$ & $115(28.9)$ & 398 \\
\hline Performing deciduous tooth restoration & - & $15(3.8)$ & $50(12.6)$ & $160(40.3)$ & $172(43.3)$ & 397 \\
\hline Performing deciduous tooth extraction & & $24(6.1)$ & $34(8.7)$ & $163(40.8)$ & $172(43.8)$ & 393 \\
\hline Taking impression & - & $6(1.5)$ & $59(14.8)$ & $297(74.6)$ & $36(9)$ & 398 \\
\hline Constructing partial denture & - & $20(5)$ & $174(43.5)$ & $177(44.5)$ & $27(6.8)$ & 398 \\
\hline Constructing complete denture & $4(1)$ & $158(39.5)$ & $97(24.7)$ & $121(30.8)$ & $13(3.3)$ & 393 \\
\hline Preparing tooth for metal ceramic crown & $48(12)$ & $148(37)$ & $90(22.5)$ & $87(21.8)$ & $27(6.8)$ & 400 \\
\hline Constructing removable appliance & $1(.3)$ & $24(6.1)$ & $59(15.1)$ & $257(65.6)$ & $51(13)$ & 392 \\
\hline Orthodontic diagnosis and treatment planning & $2(.5)$ & $27(6.8)$ & $36(9.1)$ & $239(60.5)$ & $91(23)$ & 395 \\
\hline $\begin{array}{l}\text { Treatment of different malocclusions using removable } \\
\text { appliance }\end{array}$ & - & $11(2.8)$ & $21(5.3)$ & $300(75.6)$ & $65(16.4)$ & 397 \\
\hline Preparing class 1 , class 2 , class 3 , class 4 and class 5 cavities & - & $3(.8)$ & $105(26.4)$ & $263(66.2)$ & $26(6.5)$ & 397 \\
\hline Restoring class 1 , class 2 , class 3 , class 4 and class 5 cavities & $2(.5)$ & $4(1)$ & $87(21.9)$ & $269(67.3)$ & $35(8.8)$ & 397 \\
\hline $\begin{array}{l}\text { Performing root canal treatment }(\mathrm{RCT}) \text { of anterior and posterior } \\
\text { teeth }\end{array}$ & - & $4(1)$ & $49(12.3)$ & $244(61.5)$ & $100(25.2)$ & 397 \\
\hline Performing extraction of anterior and posterior teeth & - & - & $16(4)$ & $269(67.8)$ & $112(28.2)$ & 397 \\
\hline Performing minor surgery cysts, tumors, apisectomy etc. & - & $32(8.1)$ & $66(16.7)$ & $234(59.1)$ & $64(16)$ & 396 \\
\hline
\end{tabular}

(VD=Very dissatisfied, $\mathbf{D}=$ Dissatisfied, $\mathbf{N S N D}=$ neither satisfied nor dissatisfied, $\mathbf{S}=$ Satisfied, $\mathbf{V S}=$ Very satisfied)

\section{Discussion}

The study revealed that the majority of the teachers $98 \%$ mentioned that the course duration (4 years) in comparison to number of subjects and contents is not adequate and according to $98 \%$ teachers' opinion the total course duration should be 5 years. On the other hand (97.3) students mentioned that the total course duration of undergraduate BDS course 4 years is not adequate. Regarding community placement $97 \%$ teachers mentioned that students should be placed in community setting and $63 \%$ mentioned that it should be 4 weeks. According to $93.7 \%$ students mentioned that 5 days community placement in Dental Public Health is not adequate. $87 \%$ teachers mentioned that the total hours for practical/clinical classes in individual subject are inadequate. $63 \%$ teachers mentioned that the total hours for lecture classes in individual subject are inadequate. Regarding the assessment system in different subjects both majority teachers and students mentioned that marks allocated for MCQ, SAQ, SOE, OSPE, OSCE are adequate. Majority $97 \%$ of the students mentioned that the educational environment is satisfactory. The overall results regarding the competency acquired by the newly passed dental graduate from the BDS course was satisfactory but some problematic areas were highlighted which interfered in achieving their satisfaction on their competencies. To improve the situation some changes in administrative, logistic and other areas of the institutes are suggested. The duration of the BDS course should be increased as well as the curriculum should be restructured. The duration of the community placement should be increased for community based learning. More emphasis should be given on clinical teaching hours and teaching learning strategies. A study done by Vasanthakumar et al. ${ }^{1,2}$ (2014) showed that a total of 178 students participated in the survey procedure. The response rate was $100 \%$ shows the responses and opinion of students toward the revised BDS curriculum. Majority of the students $(88 \%)$ were aware of the change in curriculum. All the students felt that internship was vital to the BDS course and $98 \%$ of them wanted to revert back to the four years and one-year internship system, $87 \%$ believed that the subsequent increase in clinical quota did not compensate for the lack of internship, and $82 \%$ also felt that it did not affect the learning experience by extending the course by a year.

Bangladesh Journal of Medical Education 2016;7(2):28-33. 
Souza et al. (20120 showed that $76 \%$ of the evidence were developed by means of quantitative studies without application of a validate instrument (68\%). The content of the 25 articles analyzed and categorized as: Perception about educational and social environment to evaluate an undergraduate curriculum (68\%); Evaluating students' ability and their academic interests to analyze his/her academic training (24\%); Problem-Based learning in health undergraduate courses as a possibility for perspective of learning (8\%). Bazen et al. ${ }^{3,4}$ (2007) showed that Students' perceptions of different issues that related to rural practice, including the differences between rural and urban practice, differences in the patient based and the perceived reasons for unsuccessful recruitment of rural practitioners were evaluated through a series of open-ended questions. More than $78 \%$ of students reported never having experienced rural life before their placement. The qualitative data indicated that the perceived advantages of rural practice including broader scope of treatment needed and the relaxed and friendly atmosphere. The commonly perceived disadvantages of rural practice were the lack of technical and specialist support, longer waiting lists for patients and lower availability of equipment. The differences in the patient base were also noted, including that rural patients were commonly perceived as friendlier as and less demanding than their urban counterparts; a higher percentage of Aboriginal patients; generally poorer overall health; and a short-term outlook on treatment methods. Robert. et. al. ${ }^{5,6,7}$ (2004) showed that not all educators agreed that matching teaching methods to a preference or style improves learning. Some researchers have suggested that the strongly preferred mode may not always be the best way to learn, depending on particular circumstances. Grasha and Stellwagen indicate that the indiscriminate use of learning style inventories may result in students thinking that they are linked to one particular style or group of styles. This undue focus may obscure the understanding that learning style evolves over one's life and one's academic/professional career. Priya et. al. ${ }^{8,9}$ 2011) showed that the purpose of this retrospective study was to evaluate the quantitative assessment of a structured essay and standardized oral examination and its correlation to the final-year graduating exam in the Department of Pediatric Dentistry, Meenakshi Ammal Dental College and Hospital, Chennai, India. The records of 531 students from 2005 to 2009 were collected. Students were categorized based on their "completion" and "grading" in a structured essay and standardized oral examination, which is a continuous assessment of dental students in the college. The grades obtained by continuous assessment were compared to students' final-year examination scores. The assessment showed that students who completed all tasks and had desirable performance in their written assessment and standardized oral examination also scored better on their final examination. Therefore, the continuous assessment by written assessment and standardized oral examination had a direct relationship to students' performance on the final examination and is useful for evaluation. Fazel, et. al. ${ }^{9,10}$ (2008) showed that out of 300 questionnaires distributed in the 30 provinces of the country,
250 questionnaires (83\%) were returned. While most of the participants considered the competencies as necessary for an Iranian dentist, less than $40 \%$ of the respondents believed that the graduates acquire the most required competencies of the profession during the current educational program.

\section{Discussion on In-depth interview (Qualitative part)}

The qualitative analysis or in-depth interview was done for when there were probe deeply about unknown aspect of a problem. The teachers were given their own opinion in their own word, there were not given any restriction or they were not rigid about the questionnaire. Where were asked the questions to the teachers, they were very cooperative with me or interested with it. Aim of in-depth interview was to explore the factors them to achieve and also constraints which was not influence them about the perceived level of satisfaction from their competencies, causes and how to improve the existing situation. Majority of the teachers felt that duration of undergraduate BDS course in comparison to subjects and contents (4 years) is not adequate and the duration should be 5 years. According to their opinion the subjects having excessive contents that should be separated. Such as periodontology and oral pathology should be separated, general and dental pharmacology should be separated; conservative dentistry and dental radiology should be separated due to excessive contents. Regarding community placement the teachers opinion was that the duration of community placement was inadequate and according to the majority teachers opinion the duration should be 21 days for community based learning. In the present curriculum the hours allocated for practical and clinical teaching were not adequate, so the teachers suggestion were, more hours should be allocated for clinical and practical teaching.

\section{Conclusions}

This descriptive cross-sectional study was carried out to explore teachers and students views regarding the present undergraduate dental curriculum in Bangladesh and the positive and negative factors responsible for achieving desired competencies of the newly passed dental graduates. Moreover, the opinion of the basic science, Para-clinical and clinical teachers and undergraduate dental students regarding for the further improvement of the undergraduate dental curriculum .The study emphasized the areas of improvements in the curriculum as well as the institute and also need of change in the dental curriculum. In the present study, the students reported that they have acquired greater practical and clinical experiences in few areas from the curriculum of BDS course. The majority of the students were not satisfied on their acquired competencies in most of the areas after their graduation. This was due to shortage of course duration in comparison to number of subjects and contents, improper distributions of the subjects, inadequate duration of community placement, less allocation of hours in practical and clinical classes etc.

Bangladesh Journal of Medical Education 2016;7(2):28-33. 
According to their opinion, lack of supervision and feedback in the clinical class, improper method of clinical assessment system of the students in all level are the responsible factors so that the students were not satisfied with the overall undergraduate BDS curriculum. Lastly it can be concluded that the graduate dentists must need to acquire sufficient competencies in most of the clinical areas for providing proper service to the community. There are many areas for further improvement through evaluating and developing the undergraduate BDS curriculum and strengthening the practical and clinical environment in the dental institutes.

\section{References}

1. Growth of the electiveprogramme. Trends in the curriculum. The Centre for Medical Education, Sydney. Pp.4450.

2. BARROWSH, .S. (1973) Problem based learning in medicine. MD Programme, Faculty of Medicine, McMaster University Education Monograph. BARROWSH, .S.\& TAMBLYNR, .M. (1980)

3. Problem-Based Learning: an Approach to Meakal Education. Springer Publishing Company Inc., New York. BENBASSATJ,. \& COHEN,R . (1982) Clinical instruction and cognitive development of medical students. Lancet, i, 95.

4. BENOR, D.E. (1982) Interdisciplinary integration in medical education: theory and method. Medical Education, 16, 355.

5. CASSILETHB, .R. \& EGAN,I .A. (1979) Modification of medical student perceptions of the cancer experiences. Journal of Medical Education, 54, 797.

6. MELVILLEA, . \& JOHNSONC, . (1982) Cured to Death. Secker and Warburg, London. RICHARDSONI.,M . (1982) Consumer views on the medical curriculum: a retrospective study of Aberdeen graduates. Medical Education, 17, 8 .

7. STEWARDJ,. \& RICH,S . (1976) The elective curriculum at Stanford University: report on the first three graduating classes. In Recent Trends in Medical Education (E. PurceU) Joshua Macey Foundation, New York. Pp. 127-143.

8. Plasschaert AJM, Lindh C, McLoughlin J, et al. Curriculum structure and the European Credit Transfer System for European dental schools: Part 1. Eur J Dent Educ 2006: 10: 123130.

9. Falk-Nilsson E, Walmsley D, Brennan M, et al. 1.2 Cognition and learning. Eur J Dent Educ 2002: 6 (Suppl 3): 2732 .
10. Ramsden P. Learning to teach in higher education. Padstow, Cornwall: TJ International Ltd, 2000.

11. Barrows HS, Tamblyn RM. Problem-based learning. An approach to medical education. New York: Springer Publishing Co, 1980.

12. Albanese MA, Mitchell S. Problem-based learning. A review of the literature on its outcomes and implementation issues. Acad Med 1993: 68: 581.

13. Maudsley G. Do we all mean the same thing by 'problembased learning'? A review of the concepts and a formulation of the ground rules. Acad Med 1999: 74: 178185.

14. Hoad-Reddick G, Theaker E. Providing support for problem-based learning in dentistry: the Manchester experience. Eur J Dent Educ 2003: 7: 312.

15. DfES. Harnessing technology: transforming learning and children's services. 2005: Available at: http://www. dfes.gov.uk/publications/e-strategy/docs/estrategy.pdfaccessed on 28 May 2007.

16. Davenport ES, Williams CE, Sterne JA, et al. An innovation in the assessment of future dentists. Br Dent $\mathrm{J}$ 1998: 184: 192195.

17. Brown G, Manogue M, Martin DM. The validity and reliability of an OSCE in Dentistry. Eur J Dent Educ 1999: 3: 117125.

18. Schoonheim-Klein M, Walmsley AD, Habets L, van der Velden U, Manogue M. An implementation strategy for introducing an OSCE into a dental school. Eur J Dent Educ 2005: 9: 143149.

19. Elangovan S, Allareddy V, Singh F, Taneja P, Karimbux N. Indian dental education in the New Millennium: Challenges and Opportunities. J Dent Educ 2010;74:101.

20. Tandon S. Challenges to the oral health workforce in India. J Dent Educ 2004;68:28

21. Ryding HA, Murphy HJ. Assessing outcomes of curricular change: A view from program graduates.JDentEduc2001;65:422-6. Baum BJ.

22. The dental curriculum: What should be new in the $21^{\text {st }}$ century? J Public Health Dent 1996;56:286-90.

23. Mahal AS, Shah N. Implications of the growth of dental education in India. J Dent Educ 2006;70:884-91.

24. Kadagad P, Tekian A, Pinto PX, Jirge VL. Restructuring an undergraduate dental curriculum to global standardsa case study in an Indian dental school. Eur J Dent Educ 2012;16:97-101.

Bangladesh Journal of Medical Education 2016;7(2):28-33. 